\title{
RESEARCH OF PARAMETER MONITORING SYSTEM IN SUGAR BOILING PROCESS
}

\author{
Jianjun $\mathrm{Su}^{1}$, Yanmei Meng ${ }^{2}$, Huaqiang $\mathrm{Qin}^{2}, \mathrm{Xu} \mathrm{Kai}^{1}$ \\ ${ }^{1}$ College of Mechanical Engineering, Guangxi University, China; E-mail: \\ gxumengyun@163.com. ${ }^{2}$ School of Light Industry and Food Engineering, Guangxi \\ University, China.
}

Abstract: $\quad$ Sugar Boiling is a most important link in producing sugar. The quality of it direct influence product. Its production line is a complicated chemistry and physics processes. The super saturation and Brix of confection in sugar boiling process, sugar boiling bowl's temperature, press...etc. Various factor effects mutually and hard to reasonable control. This paper makes use of the technique of virtual apparatus to set up on-line detection and control system of sugar boiling process, making use of the high definition of the virtual apparatus and the characteristics of easy to progress data handling, making the monitor system to have strong data amendment and analyzed processing abilities. At the same time the super saturation of confection is used as the detection and the control objects in the article, which to research the method to eliminate Brix and temperature effect of confection when measures the super saturation with method of conductance in sugar boiling process. Adopt the artificial neural network method to deal with the output of super saturation sensor by data fusion method. Using the measured value of electricalconductivity sensor, measured value of Brix and temperatures as the inputs, the network is trained by improvement BP algorithm to achieve the comparatively precision and stabilization output. The results of test shows that the data fusion method based on the artificial neural network could effectively eliminate the change of Brix and temperatures has influenced on the super saturation. Combine virtual technique of apparatus and data fusion techniques can useful exaltation the on-line detection and control techniques in sugar boiling process, carry out its process optimization control.

Key words: Virtual apparatus; super saturation; data fusion; neural network

The research is supported by Guangxi Province Nanning Key Technology Research Project

Please use the following format when citing this chapter:

$\mathrm{Su}$, Jianjun, Meng, Yanmei, Qin, Huaqiang, Kai, Xu, 2006, in International Federation for Information Processing (IFIP), Volume 207, Knowledge Enterprise: Intelligent Strategies In Product Design, Manufacturing, and Management, eds. K. Wang, Kovacs G., Wozny M., Fang M., (Boston: Springer), pp. 582-590. 


\section{INTRODUCTION}

The craft of Sugar Boiling is a most important link in producing sugar. The quality of it direct influence product. Its production line is a complicated process. This process include heat transfer and mass transfer, is a complicated chemistry and the physics processes, include various factor effects mutually. The core of sugar boiling craft is to control the super saturation of syrup. And adjust the parameters, such as temperature, press of sugar boiling process and the liquid potential...etc., to carry out its process optimization control. The boil sugar automatic system has already had the more applications abroad, but its equipment devotion is huge. The automatic control boil sugar system that is manufacture by domestic didn't yet see up to now. The great majority plant still depends on extracting sampling bar to get material, observing and judging the crystal dimension on the sheet glass and the content of sweet in the mother liquor, judging the degree of the further absorption and the value of sugar liquid plumb degree, and judging the operation of the next move on these grounds. The technical of boiling sugar is learning by teaching, this kind of method although go its availability, but can't get away from the man-made factor always. And can't carry on the large-scale production of automation forever, can't compare to with abroad on size and stable product quality, even can't compete. So the research of automatic detection and control system in keeping with domestic sugar production line has the realistic and important meaning. Because the control parameters in boil sugar production line are too many and mutual influence of this parameters is greatly, there are bigger limit to carry out the whole control of boiling sugar process with the traditional detection and control meter. Virtual apparatus is an all-new concept apparatus, which are deep combines computer technology with technique of apparatus. It is an effective coalescent of computer resource (processor 、 memory 、 display) 、 Hardware of apparatus (D/A $A / D$ 、 the digital input and output timing and signal processing etc) and the software using for data analysis the process communication and graphic user interface. It made use of the storage and the calculation functions of the calculator well, passing the software to carry out analyzing and treating input signal. The virtual apparatus software's programming environment provided a full space for the user's capacity and imagination force. You can bases the conceive and request of your to design 、 sets up own apparatus system get across programming. After establish hardware platform, the virtual apparatus can pass the change of software's mode to adapt different request. Its function is vivid and opens, easy to connect with other establish outside the network, constituting a stronger system. It can upgrade of apparatus and system along with the development of the computer technology and the requirement of consumer, 
has advantage in capability maintenance and vivid configuration etc that the traditional apparatus can't compare to, and throw in little, yield results greatly. The main research of this paper adopts the technique of virtual apparatus and data fusion to development detection and control system of sugar boiling process.

\section{TECHNIQUE OF MAIN PARAMETER MONITOR IN SUGAR BOILING PROCESS.}

\subsection{Main control parameter in sugar boiling process.}

The main mission of boiling sugar is that using hot function which produce by heating steam in sugar bowl to condense the syrup (or molasses) to the certain super saturation, separate out muster sugar crystal and keep it greatly, boil the good confection. Pass through again help crystal and use the centrifuge removal to eliminate mother liquor, acquire good quality of granulated sugar. The key operation of boiling good confection is to control the super saturation of mother liquor in boiling confection, make the sedimentation velocity of sugar phase equilibrium. Integrate the method of the boiling sugar, can induce for 4 main factors of following: 1. Hold vacuum、the press of steam、the concentration of input and the temperature stabilizations; 2、Insure the good backward flow of confection which are boiling; 3、Control the super saturation adequate; 4 、Boil the confection becomes tight. To carry out the automatic control of boiling sugar process, must monitor this a few main parameters: the super saturation of confection 、 temperature of boiling sugar bowl liquid place, press of steam, degree of vacuum...etc.

\subsection{The main parameter detection and control system in boiling sugar process.}

It can adopt the control method which use control super saturation as the core in boiling sugar process, and attain to the request control as follows: (1) Measure the liquid level of the syrup or confection continuously, for the purpose of the serve of automatic feed; (2) Control super saturation depend measure the conductivity of conductance or the value of not conduct electricity continuous; (3) Continuous control the absolute pressure in sugar bowl; (4) Continuous control the serve of steam in the whole boiling sugar process; (5) Continuous control the temperature of confection; (6)Measure the power dissipation of the agitate machinery automatically, on these grounds let it condense to the most suitable value of sugar liquid plumb 
degree before put it in sugar bowl further. The main parameter monitoring system of boiling sugar process is shown in Figure 1.

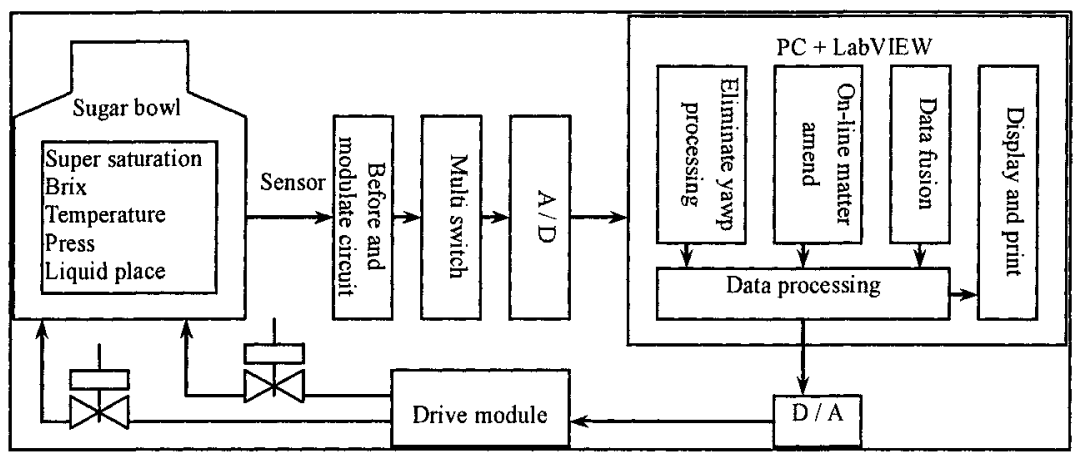

Figure 1. Main parameter on-line detection and control system

Detection and control system include inspect measure and control. The main parameters of boiling sugar process such as super saturation, Brix, temperature, press and liquid place etc., those are converted as electricity passes homologous sensor. It then pass beforehand modulate circuit and multiplex select switch, make use of the A/ D circuit transform it as digital signals, enter computer treating system to go along data handling. Result can display on computing and print. Then the signals, which have been dispose, pass D/ A conversion and drive circuit to adjust the valve switch. Thus carrying out to the automatic control of boiling sugar process. Detection and control system make use of the high definition of the virtual apparatus and the characteristics of easy to processing data well, make it have the function of strong data analyzed processing and amend. It can eliminate yawp in meterage and accurate amend the date which have error. For example it can compensate the measure cold end of thermoelectric couple that use for measure temperature and amend the nonlinear of measure, it can do date fusion with super saturation which effect by temperature and Brix bigger. It raised the accuracy and the reliability of detection data consumedly.

\section{ON-LINE DETECTION TECHNIQUE OF SUPER SATURATION}

Boil sugar this production link is very important in refine sugar industry produce. The syrup through compression, vaporize and other chemistry treating, complete fluid- solid convert in the crystal pot finally. The syrup is placed in metastable section of super saturation and born finished product 
sugar by crystal gradually. Boil sugar process change constantly because of the change of material degree and concentrations. The craft condition of boiling sugar such as Brix of confection, wave motion of temperature or steam press, this factor affected the super saturation of syrup directly. From the craft of refine sugar we can know, the key of keeping the quality of boiling sugar is to control super saturation of syrup and keeping in adequacy range. The sensors of conductance can on-line measure the super saturation. But use the conductance method measure the super saturation is under the influence of the Brix of confection and the temperature of boiling sugar. But we can use method of data fusion that is base on neural network to eliminate this influence.

\subsection{Method of data fusion about super saturation}

The electrical-conductivity sensor is placed in the boiling sugar bowl to measure super saturation of syrup, while a Brix sensor and a thermocouple that respectively measured the Brix and temperature of syrup are added to eliminate the influence. The super saturating is regarded as object parameter and the Brix and temperature of syrup are interferential parameters. Then the three parameters would be dealt with by data fusion to achieve the objective output. The frame of data fusion system is shown in Figure 2. In Figure 2, the outputs of super saturation sensor, Brix sensor and temperature sensor are $U_{1}, U_{2}$ and $U_{3}$ respectively, B shows super saturation with no disposal, Bs shows the super saturation dealt with the method of data fusion.

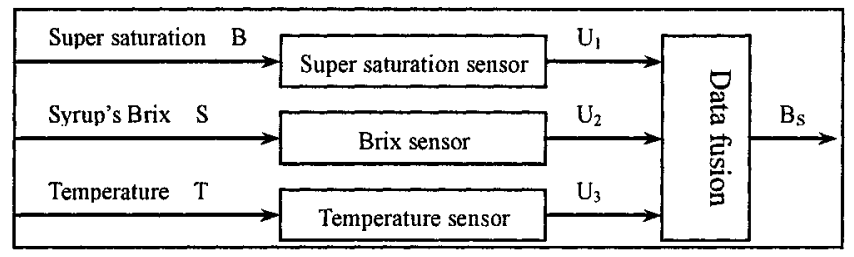

Figure 2. The model of date fusion system

\subsection{BP forward neural network algorithm}

Back Propagation network (BP network) is used widely in the models of neural network. The BP network is made up of three layers included input layer, hidden processing layer and output layer. The layers is interlinked all, and inside a layer, each neuron is not connected one another. The BP network has the great capability of nonlinear mapping and paradigm function; furthermore, any continuous function or mapping could be implemented by three-layer BP network. According to the research, the 
output of network is linear combination of a set of weight value、 threshold value and input value. The network could approach any continuous function when the function of hidden processing layer has differential coefficient with any step. Then the multi-sensor data could be fused by using a three-layer neural network which would be trained by optimized BP algorithm. BP algorithm that belongs to the $\delta$ algorithm is a surveillant type algorithm and its main theory is: for the input swatches that will be learned $\left(p^{1}, p^{2}, \cdots\right.$, $\left.\mathrm{p}^{\mathrm{q}}\right)$, corresponding output swatches $\left(\mathrm{T}_{1}, \mathrm{~T}_{2}, \cdots, \mathrm{T}_{\mathrm{q}}\right)$ is known, then, the learning objective of network is to modify the weight value by using the error between the actual output $\left(A_{1}, A_{2}, \cdots, A_{4}\right)$ and target vector $\left(T_{1}\right.$, $\mathrm{T}_{2}, \cdots, \mathrm{T}_{\mathrm{q}}$ ) in order to achieve the least sum of errors' square. The BP algorithm approaches the objective by continuously computing the weight value of network and the change of error along the decreased direction of error function's slope. Each change of weight value and error become the direct proportion with the influence of the network error. And it transfers to each layer in the way of reverse spread. BP algorithm is composed of two parts, forward transfer of information and reverse spread of error. In the forward transfer, the information of input is transferred passing the hidden processing layer from the input layer to the output layer. The outputs of each layer's node act on the inputs of next layer's node. If the output layer couldn't get the anticipant value, BP would compute the change value of output layer and turn to back propagation and then modify the node's weight value of each layer to achieve the anticipant objective according to the error signal's feedback which has been back from quondam connected gateway. The algorithm of reverse transfer is used widely but its long training time tends to plunge the partial infinitesimal because it is limited by using the gradient-descent method. The training of BP network substantively is an optimized problem about nonlinear objective function. And if the weight values of BP network could be trained by using the algorithm based on the method of numerical optimization, a faster convergent speed than using the gradient-descent method would be attached. Levenberg-Marquardt algorithm (LM) has been adopted to train the network at the same time. The search direction of LM method is given as follows.

$$
\begin{aligned}
& X^{(k+1)}=X^{(k)}+\eta^{(k)} S\left(X^{(k)}\right) \\
& S\left(X^{(k+1)}\right)=\left(H^{(k)}+\lambda^{(k)} I\right)^{-1} \nabla f\left(X^{(k)}\right)
\end{aligned}
$$

Where $X^{(k)}$ is a vector merging the all power and offset in the network, $S\left(X^{(k)}\right)$ is the search direction of $X$ vector, $\eta^{(k)}$ is the min step of $f\left(X^{(k+1)}\right)$ with the direction $f\left(X^{(k+1)}\right)$.

If $\eta^{(k)}=1$, then $X^{(k+1)}=X^{(k)}+S\left(X^{(k)}\right)$. The strongpoint of LM is that the network converges quite quickly as less weight value. 


\section{3 Test Data Fusion and Analysis of the Conclusion}

At first the demarcated test is taken to attain the output $\left(U_{1}\right)$ of super saturation sensor with different super saturation in the specifically Brix and temperature, the output $\left(\mathrm{U}_{2}\right)$ with different syrup's Brix in the specifically super saturation and temperature and the output $\left(U_{3}\right)$ with different temperature in the specifically syrup's Brix and super saturation. And then the demarcation value will be used to train the network and enforce data fusion so as to achieve the exacter information of super saturation.

According above theory, a three-layer BP network has been created to achieve the data fusion by using the Neural Network Toolbox of MATLAB and the fused result would be transferred to the foregrounding of measurement by the interface of LabVIEW and Matlab. There are three nodes on the input layer and one node in the output. In the network the tansig function is taken to activate from the input layer to hidden processing and the purelin function is used to activate from the hidden processing layer to the input layer. Firstly the input data of network must be done with unitary method to ensure the network's convergence. In this way, the three inputs are U1, U2 and U3 with unitary disposal and the output is Bs that has dealt with data fusion. Having done with the data, the network could be trained by the date of swatch database. It couldn't be convergent after 10000 steps using the non-optimized gradient-descent method, while it only need 1804 steps to attain the convergent precision quickly by using the LM algorithm. The measured value of super saturation sensor and fused results used the network with different Brix in the especially temperature (375k) are shown in Table 1.

Table 1 . The measured value and fused value of super saturation with different Brix

\begin{tabular}{|c|c|c|c|c|c|c|c|c|c|c|}
\hline \multirow{2}{*}{$\begin{array}{l}\text { Brix } \\
\left({ }^{0} \mathrm{Bx}\right)\end{array}$} & \multicolumn{2}{|c|}{$\begin{array}{l}\text { Demarcated } \\
\text { Value }=1.100 \\
\end{array}$} & \multicolumn{2}{|c|}{$\begin{array}{l}\text { Demarcated } \\
\text { value }=1.150 \\
\end{array}$} & \multicolumn{2}{|c|}{$\begin{array}{l}\text { Demarcated } \\
\text { value }=1.20\end{array}$} & \multicolumn{2}{|c|}{$\begin{array}{l}\text { Demarcated } \\
\text { value }=1.25\end{array}$} & \multicolumn{2}{|c|}{$\begin{array}{c}\text { Demarcated } \\
\text { value }=1.30\end{array}$} \\
\hline & $\begin{array}{l}\text { Meas- } \\
\text { ured } \\
\text { value }\end{array}$ & $\begin{array}{l}\text { Fused } \\
\text { value }\end{array}$ & $\begin{array}{c}\text { Meas- } \\
\text { ured } \\
\text { value }\end{array}$ & $\begin{array}{l}\text { Fused } \\
\text { value }\end{array}$ & $\begin{array}{l}\text { Meas- } \\
\text { ured } \\
\text { value }\end{array}$ & $\begin{array}{l}\text { Fused } \\
\text { value }\end{array}$ & $\begin{array}{c}\text { Meas- } \\
\text { ured } \\
\text { value }\end{array}$ & $\begin{array}{l}\text { Fused } \\
\text { value }\end{array}$ & $\begin{array}{c}\text { Meas- } \\
\text { ured } \\
\text { value }\end{array}$ & $\begin{array}{l}\text { Fused } \\
\text { value }\end{array}$ \\
\hline 75 & 0.870 & 1.090 & 1.031 & 1.147 & 1.021 & 1.199 & 1.063 & 1.236 & 1.213 & 1.295 \\
\hline 75.5 & 1.031 & 1.085 & 1.121 & 1.138 & 1.153 & 1.201 & 1.231 & 1.251 & 1.291 & 1.298 \\
\hline 76 & 1.131 & 1.110 & 1.231 & 1.149 & 1.230 & 1.205 & 1.206 & 1.249 & 1.352 & 1.306 \\
\hline 76.5 & 1.153 & 1.103 & 1.364 & 1.151 & 1.362 & 1.203 & 1.248 & 1.252 & 1.483 & 1.310 \\
\hline 77 & 1.136 & 1.105 & 1.302 & 1.156 & 1.445 & 1.202 & 1.339 & 1.251 & 1.537 & 1.312 \\
\hline 77.5 & 1.270 & 1.102 & 1.231 & 1.159 & 1.311 & 1.205 & 1.265 & 1.249 & 1.491 & 1.301 \\
\hline 78 & 1.126 & 1.109 & 1.186 & 1.499 & 1.243 & 1.219 & 1.232 & 1.248 & 1.387 & 1.306 \\
\hline $\begin{array}{l}\operatorname{Max} \\
\Delta B\end{array}$ & 0.4 & & 0.333 & & 0.424 & & 0.302 & & 0.324 & \\
\hline $\begin{array}{l}\mathrm{Max} \\
\triangle \mathrm{Bs}\end{array}$ & & 0.025 & & 0.021 & & 0.020 & & 0.016 & & 0.017 \\
\hline
\end{tabular}


Table 2 shows the measured value of super saturation sensor and fused results using the network with different temperature in the specially Brix $\left(76^{\circ} \mathrm{Bx}\right)$.

Table 2. The measured value and fused value of super saturation with different temperature

\begin{tabular}{|c|c|c|c|c|c|c|c|c|c|c|}
\hline \multirow{2}{*}{$\begin{array}{l}\text { Temp- } \\
\text { erature } \\
(\mathrm{K})\end{array}$} & \multicolumn{2}{|c|}{$\begin{array}{c}\text { Demarcated } \\
\text { Value }=1.100\end{array}$} & \multicolumn{2}{|c|}{$\begin{array}{l}\text { Demarcated } \\
\text { value }=1.150\end{array}$} & \multicolumn{2}{|c|}{$\begin{array}{l}\text { Demarcated } \\
\text { value }=1.200\end{array}$} & \multicolumn{2}{|c|}{$\begin{array}{l}\text { Demarcated } \\
\text { value }=1.25\end{array}$} & \multicolumn{2}{|c|}{$\begin{array}{l}\text { Demarcated } \\
\text { value }=1.300\end{array}$} \\
\hline & $\begin{array}{l}\text { Meas- } \\
\text { ured } \\
\text { value }\end{array}$ & $\begin{array}{l}\text { Fused } \\
\text { value }\end{array}$ & $\begin{array}{l}\text { Meas- } \\
\text { ured } \\
\text { value }\end{array}$ & $\begin{array}{l}\text { Fused } \\
\text { value }\end{array}$ & $\begin{array}{l}\text { Meas- } \\
\text { ured } \\
\text { value }\end{array}$ & $\begin{array}{l}\text { Fused } \\
\text { value }\end{array}$ & $\begin{array}{l}\text { Meas- } \\
\text { ured } \\
\text { value }\end{array}$ & $\begin{array}{l}\text { Fused } \\
\text { value }\end{array}$ & $\begin{array}{c}\text { Meas- } \\
\text { ured } \\
\text { value }\end{array}$ & $\begin{array}{l}\text { Fused } \\
\text { value }\end{array}$ \\
\hline 350 & 0.878 & 1.093 & 1.021 & 1.131 & 1.026 & 1.189 & 1.073 & 1.246 & 1.213 & 1.292 \\
\hline 355 & 1.030 & 1.082 & 1.161 & 1.140 & 1.153 & 1.201 & 1.231 & 1.251 & 1.298 & 1.304 \\
\hline 360 & 1.212 & 1.109 & 1.241 & 1.148 & 1.230 & 1.205 & 1.206 & 1.249 & 1.362 & 1.309 \\
\hline 365 & 1.156 & 1.106 & 1.379 & 1.151 & 1.362 & 1.203 & 1.248 & 1.252 & 1.417 & 1.317 \\
\hline 370 & 1.141 & 1.105 & 1.392 & 1.157 & 1.453 & 1.202 & 1.349 & 1.251 & 1.569 & 1.312 \\
\hline 375 & 1.232 & 1.112 & 1.215 & 1.149 & 1.311 & 1.205 & 1.449 & 1.249 & 1.458 & 1.310 \\
\hline 380 & 1.126 & 1.109 & 1.182 & 1.141 & 1.243 & 1.213 & 1.212 & 1.248 & 1.410 & 1.303 \\
\hline $\begin{array}{c}\operatorname{Max} \\
\Delta B\end{array}$ & 0.354 & & 0.371 & & 0.427 & & 0.376 & & 0.356 & \\
\hline $\begin{array}{l}\text { Max } \\
\Delta \mathrm{Bs}\end{array}$ & & 0.030 & & 0.026 & & 0.024 & & 0.022 & & 0.025 \\
\hline
\end{tabular}

Before it has been fused, the relative value of sensor's fluctuant output that is affected by the change of syrup's Brix is given as Eq (3),

$$
\delta=\frac{\max |\Delta B|}{B_{\text {标 }}}
$$

Where $\delta$ is the relative value of output's fluctuant electrical pressure, $\max |\Delta \mathrm{B}|$ is the max absolute value of sensor's output, $B_{\text {标 }}$ is the value of demarcating super saturation.

Having been fused, the relative value of sensor's fluctuant output is affected by the change of syrup's Brix is given as Eq (4).

$$
\delta^{\prime}=\frac{\max \left|\Delta B_{s}\right|}{B_{\text {标 }}}
$$

Where $\delta$ is the relative value of output's fluctuant electrical pressure, $\max \left|\Delta \mathrm{B}_{\mathrm{s}}\right|$ is the max absolute value of sensor's fluctuant output, $B_{d}$ is the demarcated super saturation.

From the demarcation data, the relative value of sensor's fluctuant output is $35 \%$ when the demarcated super saturation is $1.20 \%$ and the Brix changes from $75^{\circ} B_{x}$ to $78^{\circ} B_{x}$; therefore, the Brix of syrup affected its super saturation 
strongly. Having been fused, the relative value of fluctuant output is decreased to $1.7 \%$.

In the same way, the relative value of sensor's fluctuant output is $36 \%$ when the demarcated super saturation is $1.20 \%$ and the temperature changes from $350 \mathrm{~K}$ to $380 \mathrm{~K}$; therefore, the temperature affected the syrup's super saturation strongly. Having been fused, the relative value of fluctuant output is decreased to $2.0 \%$. It shows that the effect of Neural Network data fusion is distinct. The neural network method is quite availability in eliminating the effect by temperature and Brix to sensor at work.

\section{CONCLUSION}

It is convenience, fast, good quality of transplant and reuse that the online detection and control system in boiling sugar process use the open and graphics mode form of programme method to set up the system. Detection and control system also make the best of characteristics of virtual apparatus: high precision and easy to progress data handling, make it have the function of strong data amend and analyses treating. Hang together the technique of virtual apparatus and data fusion organic when measure the super saturation degree of confection organic. The method of date fusion, which is base on the artificial neural network, eliminate the influence of the change of confection's Brix and temperatures, thus get the precision、stable-measured value. The fluctuant value of super saturation sensor's fluctuant output is $30 \sim 40 \%$ without disposal, which compared with the value is less then $2.5 \%$ with data fusion; therefore, the effect of data fusion is distinct. This experimentation proves that the automatic monitoring system of boiling sugar process achieve the anticipant effect.

\section{REFERENCES}

1. Liang Zhou, Instrument and Automation of Refining Sugar Industry, Beijing: Light Industry-publishing Company, 1988.

2. Shen Yi etc. Study on Data Fusion of Bedload's Content with Capacitive Sensor [J], Journal of Huazhong Agricultural University, 2004, vol23, No4: 459 462.

3. Cong Shuang, Application of Nerve Network and Fuzzy System on Movement Control [M], Beijing: Publication of University of Science and Technology of China, 2001.

4. Qingdong Du, Lingyu Xu, Zhao Hai, Differentiate and Analyse of Pressure and Indraught System of Water and Electricity Factory Based on Neural Fusion Arithmetic [J], Control and Decision-making, 2001,16 (Subjoined): 787 789.

5. Beiping Hou, Lu Pei, Modeling and System Simulation of BP Nerve Network Based on MATLAB [J], Automation and Instrument, 2001, 16 (1): 34 36. 